\title{
Photocatalytic Reversible Reactions Driven by Localized Surface Plasmon Resonance
}

\author{
Zheng Gong, Jialong Ji and Jingang Wang * \\ Computational Center for Property and Modification on Nanomaterials, College of Sciences, \\ Liaoning Shihua University, Fushun 113001, China; gongz640@nenu.edu.cn (Z.G.); jjlzs5201314@163.com (J.J.) \\ * Correspondence: Jingang_wang@lnpu.edu.cn; Tel.: +86-18040036755
}

Received: 14 January 2019; Accepted: 18 February 2019; Published: 20 February 2019

\begin{abstract}
In this study, we review photocatalytic reversible surface catalytic reactions driven by localized surface plasmon resonance. Firstly, we briefly introduce the synthesis of 4,4'-dimercaptoazobenzene (DMAB) from 4-nitrobenzenethiol (4NBT) using surface-enhanced Raman scattering (SERS) technology. Furthermore, we study the photosynthetic and degradation processes of 4NBT to DMAB reduction, as well as factors associated with them, such as laser wavelength, reaction time, substrate, and $\mathrm{pH}$. Last but not least, we reveal the competitive relationship between photosynthetic and degradation pathways for this reduction reaction by SERS technology on the substrate of $\mathrm{Au}$ film over a nanosphere.
\end{abstract}

Keywords: plasmon; 4-nitrobenzenethiol; 4,4'-dimercaptoazobenzene; Au film

\section{Introduction}

Surface-enhanced Raman scattering (SERS) and tip-enhanced Raman spectroscopy (TERS) are widely used in the fields of physics, chemistry, biology, medicine, and materials, and they are highly sensitive molecular-detection tools that play a significant role in research on the electronic structure and spectral properties of molecules and plasmon-driven chemical reactions [1-9]. Recently, we studied the physical mechanism of plasmon-enhanced resonance Raman and fluorescence spectra [10] to understand the applications and principles of photoinduced charge transfer [11]. Furthermore, SERS made significant contributions to the study of heterostructures in two-dimensional materials [12], and significant advances were made in the application of nonlinear optical microscopy [13]. At the same time, it is a significantly important tool for probing chemical signals about molecules adsorbed onto metal substrates, such as $\mathrm{Au}, \mathrm{Ag}$, and $\mathrm{Cu}$. It is also a promising technology for detecting plasmon-driven catalytic mechanisms. This technique is extremely sensitive to detecting high field-enhancement regions on a plasmon substrate. Many research results show that an electromagnetic field is an important part of the SERS enhancement mechanism, which is generated by the amplification and localization of incident electromagnetic waves.

A lot of research shows that conversion of 4-nitrobenzenethiol (4NBT) and $p$-aminothiophenol (PATP) to 4,4'-dimercaptoazobenzene (DMAB) via reduction and oxidation reactions was achieved with SERS technology [2-11,14-18]. Theoretical and experimental studies showed that SERS synthesis of DMAB from PATP is achieved via the selective catalytic coupling of Ag nanoparticles (Ag NPs). It was concluded that, in the field of electromagnetic fields, the six strong generated vibration modes are enhanced by the plasmon; this is direct evidence of the reaction of PATP to DMAB on Ag NPs via selective catalytic coupling $[19,20]$. Therefore, DMAB is an important topic in the study of plasmon-assisted catalytic reactions [21-24].

Authors researched the effects of photoreduction-field enhancement from 4NBT to DMAB driven by plasmon on $\mathrm{Au}, \mathrm{Ag}$, and $\mathrm{Cu}$ [25-27]. The molecular structure of $4 \mathrm{NBT}$ and DMAB are shown in 
Figure 1 [28]. Studies showed that there was a higher active SERS in a diluted $\mathrm{HNO}_{3}$ solution for $\mathrm{Cu}$ substrates by using a 632.8-nm He/Ne laser. However, it could not be ruled out that $\mathrm{Cu}$ may also be an effective photoelectron emitter under a wavelength condition of $632.8 \mathrm{~nm}$. The SERS spectrum on Cu-adsorbed 4NBT could be significantly converted into an SERS spectrum of another substance, such as 4-aminobenzenethiol (4ABT). Simultaneously, the authors studied the time-, substrate-, and wavelength-dependent surface catalysis reduction reaction of $4 \mathrm{NBT}$ to DMAB under the assisting condition of plasmon on $\mathrm{Au}, \mathrm{Ag}$, and $\mathrm{Cu}$ [29]. In Figure 2, atomic force microscopy (AFM) images of $\mathrm{Au}$, $\mathrm{Ag}$, and $\mathrm{Cu}$ films are displayed. Studies showed that this kind of reduction reaction of $4 \mathrm{NBT}$ to DMAB was significantly dependent on wavelength, substrates, and reaction time. When the wavelength was $632.8 \mathrm{~nm}$, the reaction of $4 \mathrm{NBT}$ to DMAB did not occur on the $\mathrm{Cu}$ film substrate when the reaction time exceeded two hours. In contrast, $4 \mathrm{NBT}$ was quickly converted to DMAB when the wavelength was $514.5 \mathrm{~nm}$. Thus, it was rational to control this reduction reaction by adjusting some of the factors mentioned above. Plasmon hot electrons provide high kinetic energy to overcome the reaction barrier for dissociation, and the electrons for photodissociation.

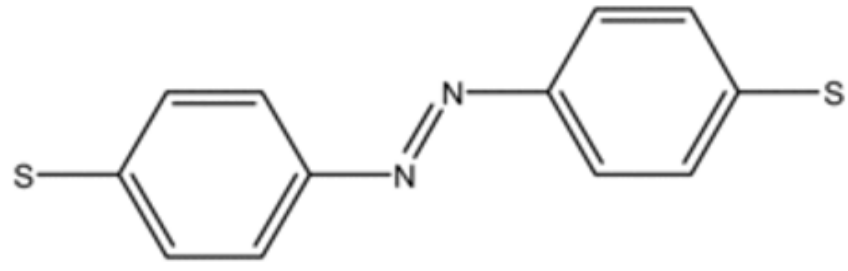

(a)

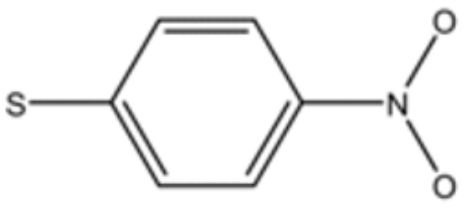

(b)

Figure 1. Chemical structures of (a) 4,4'-dimercaptoazobenzene (DMAB), and (b) 4-nitrobenzenethiol (4NBT) [28].

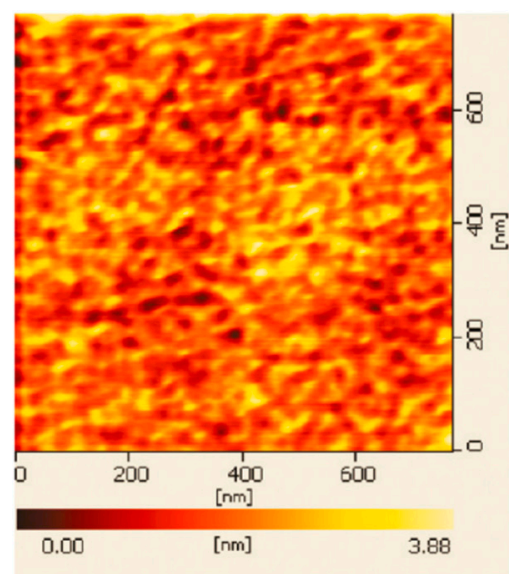

(a)

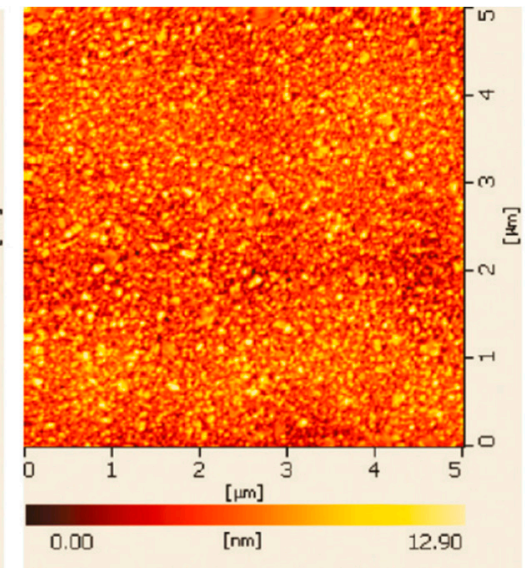

(b)

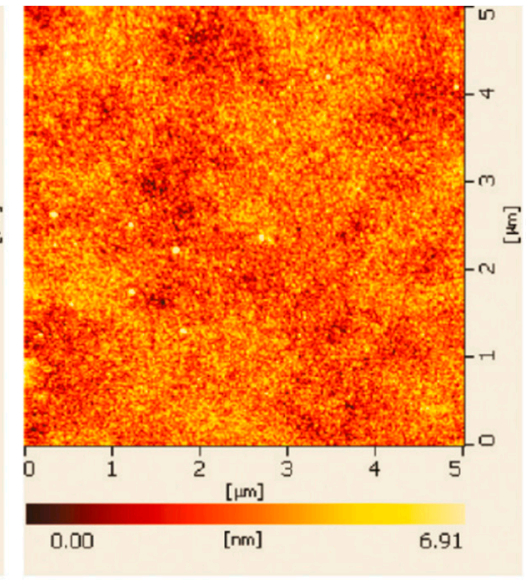

(c)

Figure 2. Atomic force microscopy (AFM) images of the (a) Au, (b) Ag, and (c) Cu films [29].

\section{Plasmon-Driven Surface Catalysis Reduction Reaction of 4 NBT to DMAB}

In this section, we focus on the time- and wavelength-dependent plasmon-driven surface catalysis reduction reaction of $4 \mathrm{NBT}$ to $\mathrm{DMAB}$ on an Au film. Sun et al. conducted some research on Au films and determined whether the rate and yield of the reaction were related to the wavelength of the used laser and the reaction time. In Figure 3a,b, SERS spectra of 4NBT are shown at the junction of an Ag $\mathrm{NP}$ on the Au film with the incident wavelength of 514.5 and $632.8 \mathrm{~nm}$, respectively. Studies showed that, when the incident laser had a wavelength of $632.8 \mathrm{~nm}$ and the reaction time reached $2.5 \mathrm{~h}, 4 \mathrm{NBT}$ did not convert to DMAB, revealed by the Raman intensity of $v_{\mathrm{S}}\left(\mathrm{NO}_{2}\right)$ on $4 \mathrm{NBT}$. When the wavelength of the incident laser was $632.8 \mathrm{~nm}$, the corresponding local electric-field distribution map of an $\mathrm{Ag}$ 
$\mathrm{NP}-\mathrm{Au}$ film was as displayed in Figure 4. However, when the incident laser wavelength was $514.5 \mathrm{~nm}$, the Raman signal was hardly detected after $2.5 \mathrm{~h}$, indicating that the Au film was not a reasonable substrate under the condition of a 514.5-nm laser.

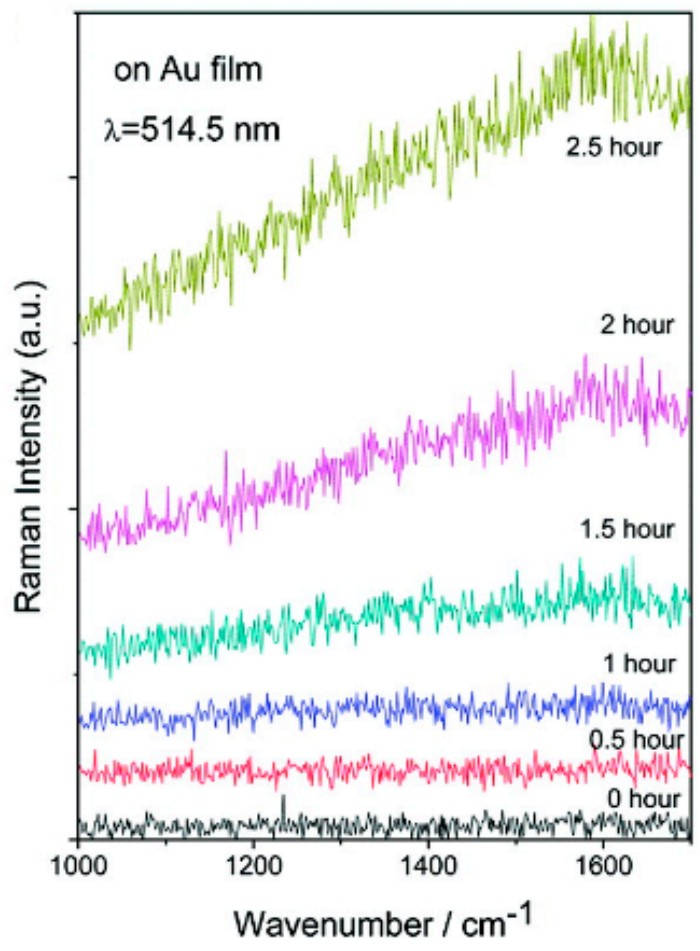

(a)

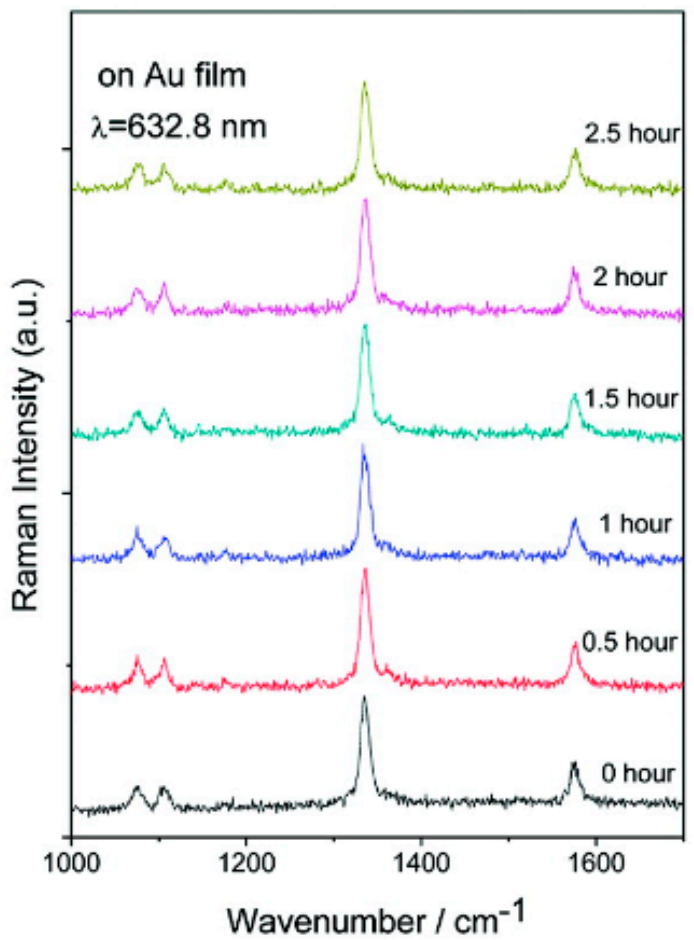

(b)

Figure 3. Surface-enhanced Raman scattering (SERS) spectra of 4 NBT at the junction of an Ag nanoparticle (NP) on the Au film at incident wavelengths of (a) $514.5 \mathrm{~nm}$ and (b) $632.8 \mathrm{~nm}$ [29].

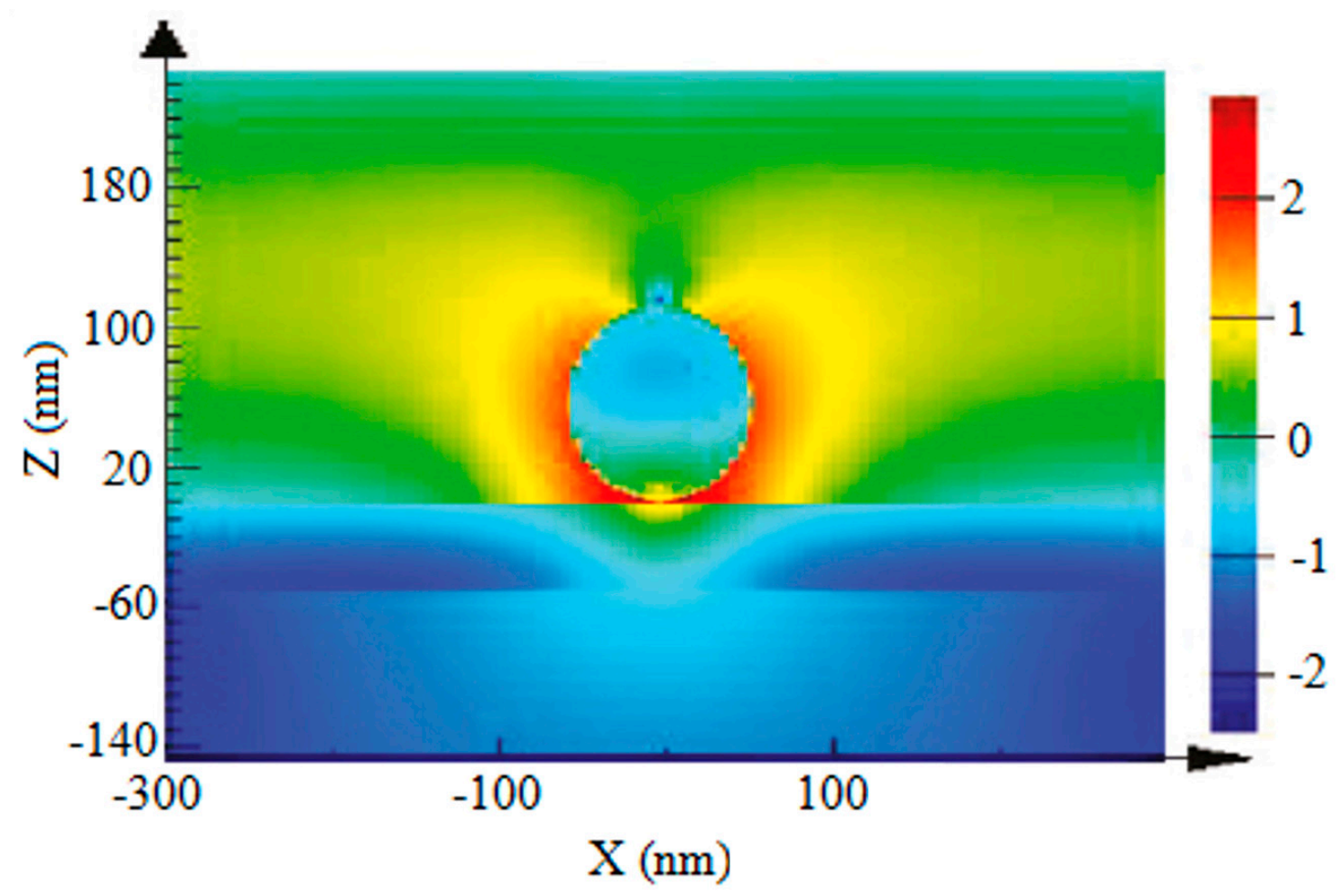

Figure 4. Ag NP-Au film at an incident wavelength of $632.8 \mathrm{~nm}$ [29]. 
Here, the authors proposed a reaction mechanism for a surface catalytic reaction when the 4NBT is transformed into DMAB, as displayed in Figure 5. There are many ways to provide energy for plasmon-driven surface catalytic reactions, such as enhanced thermal surroundings, hot electric transfer, and increased scattering. Here, the authors mainly studied energy supply by hot electrons. This mechanism indicates that the conversion of 4 NBT to DMAB requires four electrons, and the required hot electrons were generated by plasmon decay, which had high kinetic energy, and the generated energy could drive the surface catalytic reaction.

By detecting the Raman signals of different incident-laser wavelengths and reaction times, the relationship between the surface catalytic reduction reaction of 4NBT to DMAB and the length of the reaction time was shown. The wavelength of the incident laser was also revealed, thus finding the optimal incident-laser wavelength and reaction time. Therefore, these two factors can be adjusted to promote or inhibit the surface catalytic reduction of $4 \mathrm{NBT}$ to DMAB on Au substrates. At the same time, plasmon resonance plays a key role in the surface catalytic reaction, and the energy that drives the reaction is generated by plasmon decay.

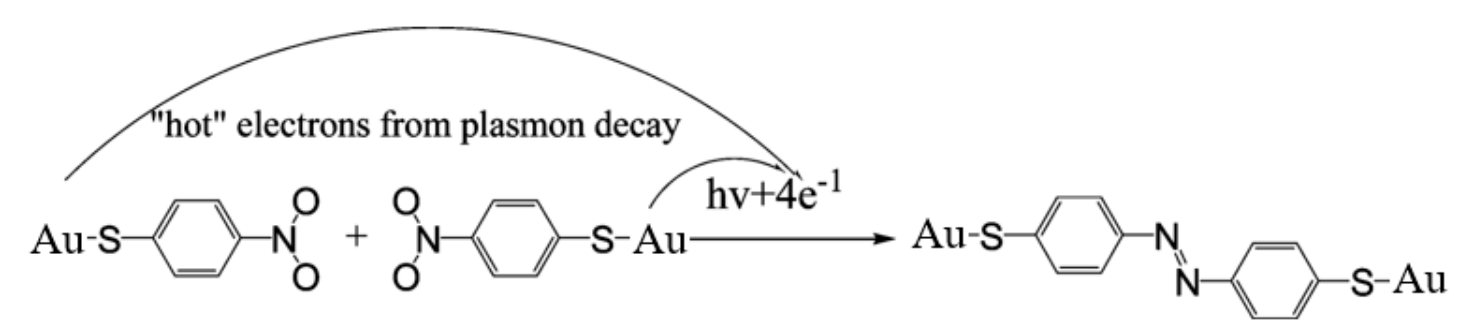

Figure 5. Mechanism of plasmon-assisted surface-catalyzed reaction [29].

In a previous study, control of the degradation reaction of DMAB was achieved, the chemical bond of DMAB was selectively broken using hot electrons as plasmon scissors, and the degradation process was related to various factors, such as $\mathrm{pH}$. The authors controlled the dissociation products by $\mathrm{pH}$, attaching hydrogen ions under acidic conditions to produce PATP. Under alkaline conditions, 4 NBT was produced by attaching oxygen ions. In the next section, we present an in-depth discussion on what was more dominant in the synthesis and degradation process under different environmental conditions, as well as what had a higher conversion rate and a faster response rate.

\section{Competition between Reaction and Degradation Pathways in Plasmon-Driven Photochemistry of 4 NBT to DMAB}

Plasmon materials are important for driving photochemical reactions. Previous studies showed that plasmon induced many photochemical reactions, but the corresponding reaction mechanism was not clear. In this section, the plasmon excitation field effect of plasmon excitation to promote the conversion of $4 \mathrm{NBT}$ to DMAB was investigated. For this reduction reaction, the increase in DMAB and decrease in 4NBT were related to time [30-32].

Plasmon nanostructures significantly contribute to driving photochemical reactions due to the powerful ability of plasmon nanostructures to focus and amplify various spectra [33-36]. Therefore, plasmon materials often act as a photocatalytic platform for inducing a lot of photochemical reactions. In previous studies, photoreactions were carried out, such as dissociation of $\mathrm{H}_{2}$ [37,38], water decomposition [39,40], and reduction of $\mathrm{CO}_{2}$ to hydrocarbon compounds [41,42]. This proved that plasmon-driven photoreactions have great potential. In this section, the authors used a substrate of $\mathrm{Au}$ film over a nanosphere $(\mathrm{AuFON})$ to measure the yield and reaction rate of $4 \mathrm{NBT}$ photoreactions. In general, more field enhancement resulted in higher reaction yields. Unfortunately, this conjecture was not proven with the current technology. Studies showed that, for molecular degradation reactions, the reaction yield is highly dependent on electric-field strength. 
To calculate the enhancement factor (EF) of each sampling area of the AuFON substrate, the specific relationship could be expressed by the following equation (Brooks, J.L., et al.):

$$
\mathrm{EF}=\frac{I_{\mathrm{SERS}} / N_{\text {surf }}}{I_{\mathrm{NRS}} / N_{\mathrm{vol}}}
$$

where $I_{\text {SERS }}$ is the Raman intensity of 4 NBT when wavenumber position is $1074 \mathrm{~cm}^{-1}$ on the AuFON substrate, and the corresponding Raman intensity in the solution is $I_{\text {NRS. }} N_{\text {surf }}$ is the number of molecules that are adsorbed onto the substrate of AuFON, and $N_{\mathrm{vol}}$ is the number of molecules in the sample collected by normal Raman scattering spectroscopy. The Raman cross-section of cyclohexane and 4 NBT was collected in previous experiments $[43,44]$.
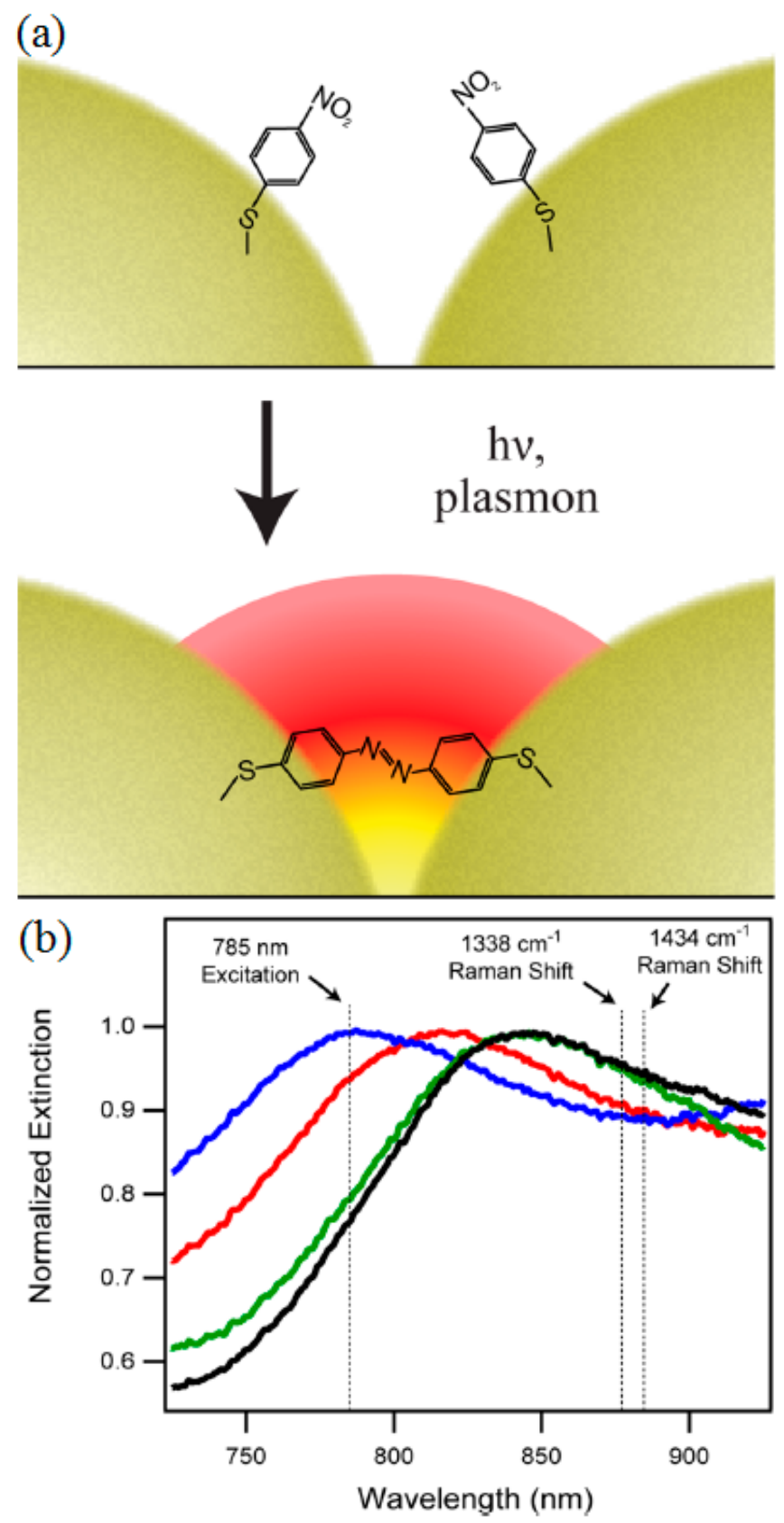

Figure 6. (a) Depiction of plasmon-driven conversion of 4NBT to DMAB; (b) localized surface plasmon (SP) measurements of SERS substrates. Different spots on the surface have varying plasmon-resonance wavelengths, affecting the SERS enhancement factor (EF) and electric-field enhancement [45]. 
The AuFON substrate used here has many advantages because it was spherical, its random variation changed the detected SERS EF, and the resulting value was the enhanced average in the selected region. The authors schematically illustrated the reaction of field-enhancement effects for plasmon-driven photoreaction on 4NBT transfer to DMAB, as shown in Figure 6a. It is shown in Figure $6 \mathrm{~b}$ that defects in the spherical fill might cause a change in the local surface plasmon resonance (LSPR) of the detection region, thereby increasing/decreasing extinction and widening at the position of the excitation wavelength. In addition, Figure $6 \mathrm{~b}$ displays the wavelength of the $785-\mathrm{nm}$ laser and the scattering wavelengths of the two important vibration modes detected during the photoreactions [45]. With the red-shift of laser wavelength, the Raman peaks at 1338 and $1433 \mathrm{~cm}^{-1}$ also changed, which revealed the relationship of surface catalytic wavelength reactions.

In Figure 7 [45], we can see the time-resolved Raman spectroscopy of 4NBT plasmon-driven photocatalytic reactions. At the beginning, the vibration pattern appeared at $1338 \mathrm{~cm}^{-1}$, as shown in the red part of the figure, indicating that $4 \mathrm{NBT}$ corresponds to $\mathrm{NO}_{2}$ symmetric stretching vibration [46]. During laser irradiation, new Raman peaks appeared at 1140, 1388, and $1434 \mathrm{~cm}^{-1}$, as shown in the green portion of the figure. This demonstrated DMAB generation, but it could be seen from the spectrum that no intermediate was produced. As reaction time increased, the DMAB peak increased and the 4 NBT peak decreased. Among them, the Raman peak appearing at a $1434 \mathrm{~cm}^{-1}$ was selected as symbolic of the growth kinetics of the reaction product because the vibration mode of such a peak was found to be a symmetric azo bond in the DMAB spectrum [47]. The authors could calculate the yield and average kinetic energy of the 4NBT-to-DMAB reduction reactions. Here, the authors estimated plasmonic-field enhancement by using SERS enhancement factors (SERS EFs) [48,49]. With the increase in radiation time, the Raman peak at $1338 \mathrm{~cm}^{-1}$ was significantly reduced, while the Raman peak at $1433 \mathrm{~cm}^{-1}$ increased, which demonstrated surface catalytic reactions.

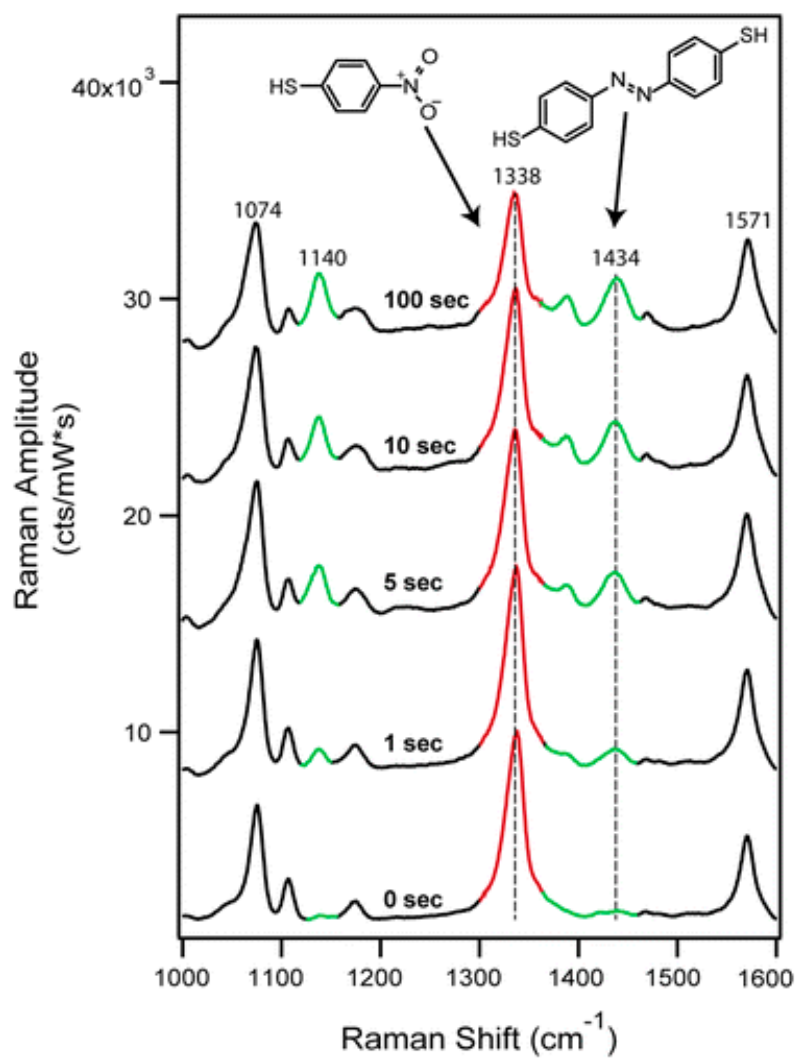

Figure 7. Time-resolved SERS measurements during the plasmon-driven conversion of 4NBT to DMAB. The reactant peak at $1338 \mathrm{~cm}^{-1}$ decays during SERS measurement, and the product peak at $1434 \mathrm{~cm}^{-1}$ grows during SERS measurement [45]. 
Figure 8 displays the variation in Raman peak amplitude during growth and decay, and plots the SERS EF function. It can be seen from the figure that the amplitude of the Raman peak during the growth process was positive, and the amplitude of the Raman peak corresponding to the attenuation process was negative. Figure 8 displays an amplitude plot of the Raman peaks of the reactants and products as a function of SERS EF. Studies showed that the change in peak amplitude of reactants and products was related to SERS EF. The Raman signal amplitude of the reactants and products increased with the increase of SERS EF when the molecule was bound to the Au surface.

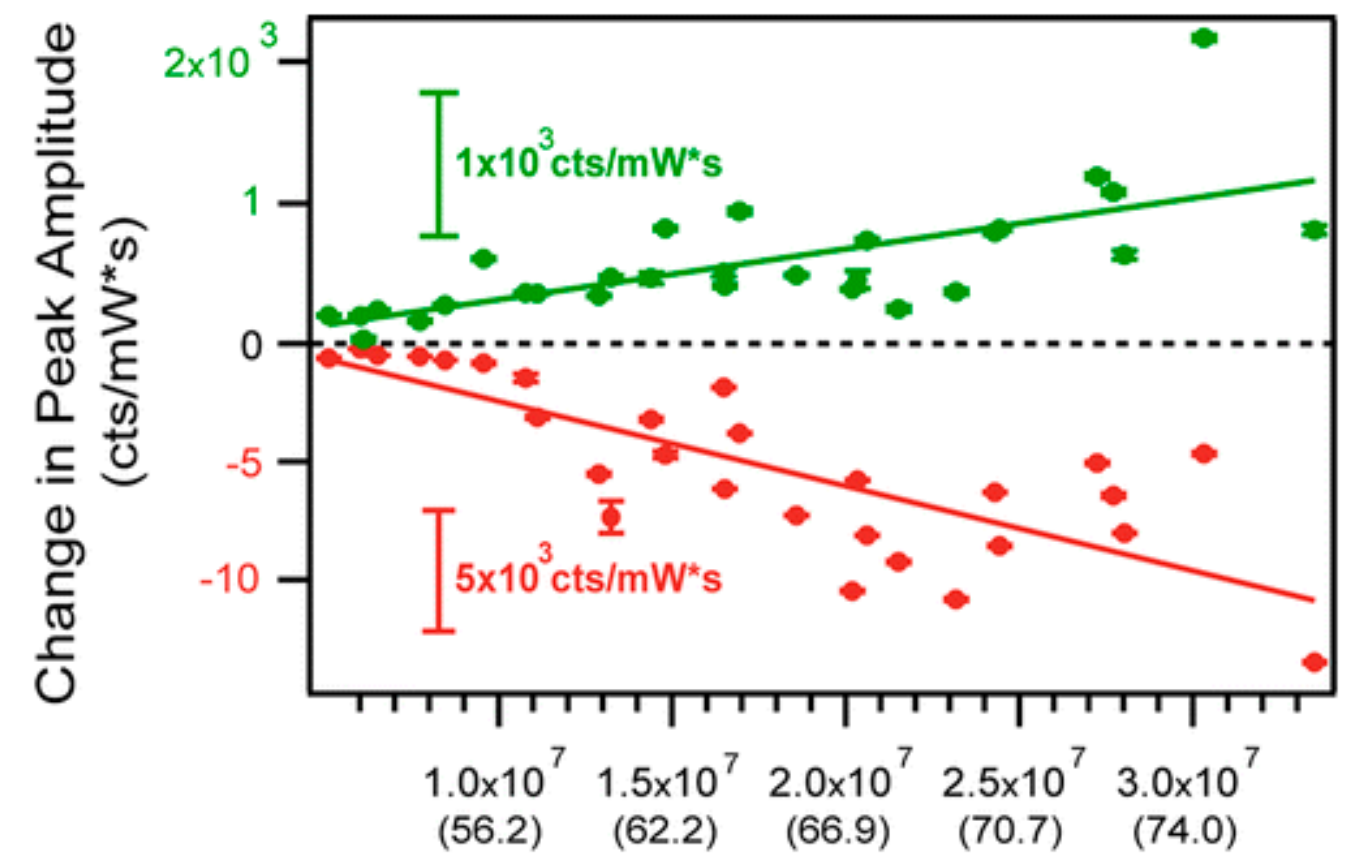

\section{SERS Enhancement Factor (Electric Field Enhancement)}

Figure 8. Total change in the reactant (red) and product (green) peak amplitudes as a function of SERS EF. The $y$-axes for reactant and product are different to clearly highlight the correlation with the SERS EF [45].

In order to further investigate the difference in reactant reduction and product increase in plasmon excitation reactions, reaction conversion efficiency and yield are proposed here. The reaction yield of the system is shown in Figure 9a, defining the ratio of the ending Raman amplitude of a product to a reactant. In fact, this was the percentage of the number of remaining 4NBT molecules on the surface when reactions were finished. There was no effect on the conversion efficiency of the SERS EF function. In this section, conversion efficiency is defined as the quotient of total product growth to total reactant reduction, where increase or decrease is expressed by the amplitude of the corresponding Raman peak. In contrast to the end-reaction yield, conversion efficiency concentrated on how intensely the reactant signal was lost, rather than recording the end amplitude. It can be observed from Figure $9 \mathrm{~b}$ that, as the SERS EF increased, conversion efficiency gradually decreased. When the intensity of SERS EF was less than $10^{7}$, conversion efficiency was between $20 \%$ and $100 \%$; when the electric field was enhanced, conversion efficiency was generally low. Figure $9 \mathrm{~b}$ displays that, when the intensity of the SERS EF was small, for example, less than $10^{7}$, the conversion rate dropped significantly. 

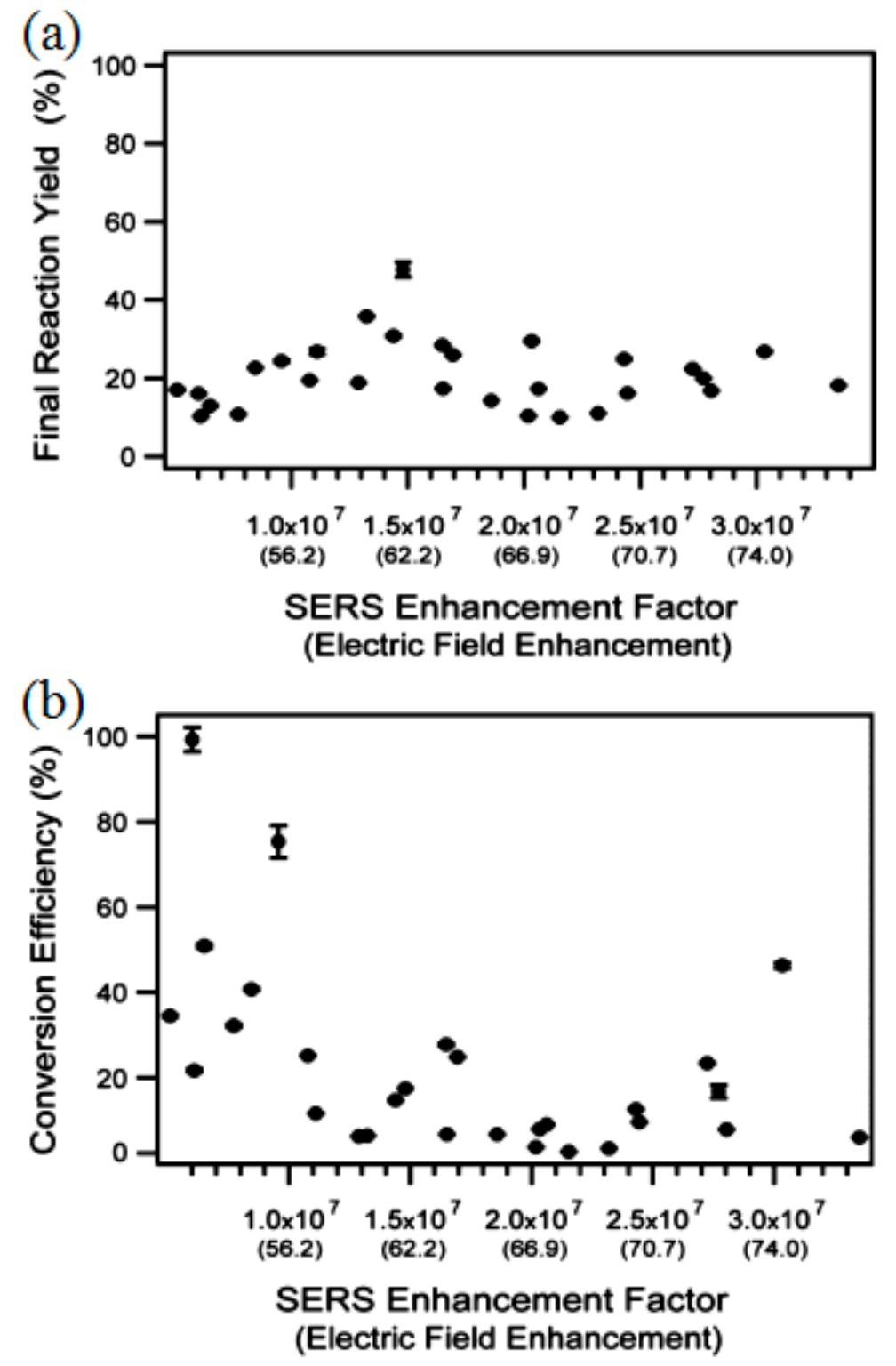

Figure 9. (a) Final reaction yield, which is the ratio between product final amplitudes and reactant amplitudes of photoreactions and dependence on SERS EF. As localized field enhancement increased, the reaction yield stayed between $10 \%$ and $40 \%$; (b) dependence of conversion efficiency, defined as the ratio between the amplitude changes of the product and reactant amplitudes on the SERS EF. As field enhancement increased, the reactant peak $\left(1338 \mathrm{~cm}^{-1}\right)$ decayed more significantly than the product peak formed $\left(1434 \mathrm{~cm}^{-1}\right)$ [45].

Since the ability of the AuFON substrate was significantly improved, a large amount of the product could quickly be collected at the beginning; thus, the authors focused on average reaction kinetics. Figure 10 displays three independent kinetic measurements of the plasmon-induced reactions of 4 NBT to DMAB, with different local field enhancements. Comparing Figure 10a-c, it can be seen that the resulting kinetics vary extensively in different areas of the substrate. Furthermore, in Figure 10a,b, product growth increased significantly within $10 \mathrm{~s}$ before the reactions, as indicated by the broken green line. In Figure 10c, we can see that the product was produced at a slower rate. It is, therefore, concluded that there was significant loss of reactant signal during product formation. 

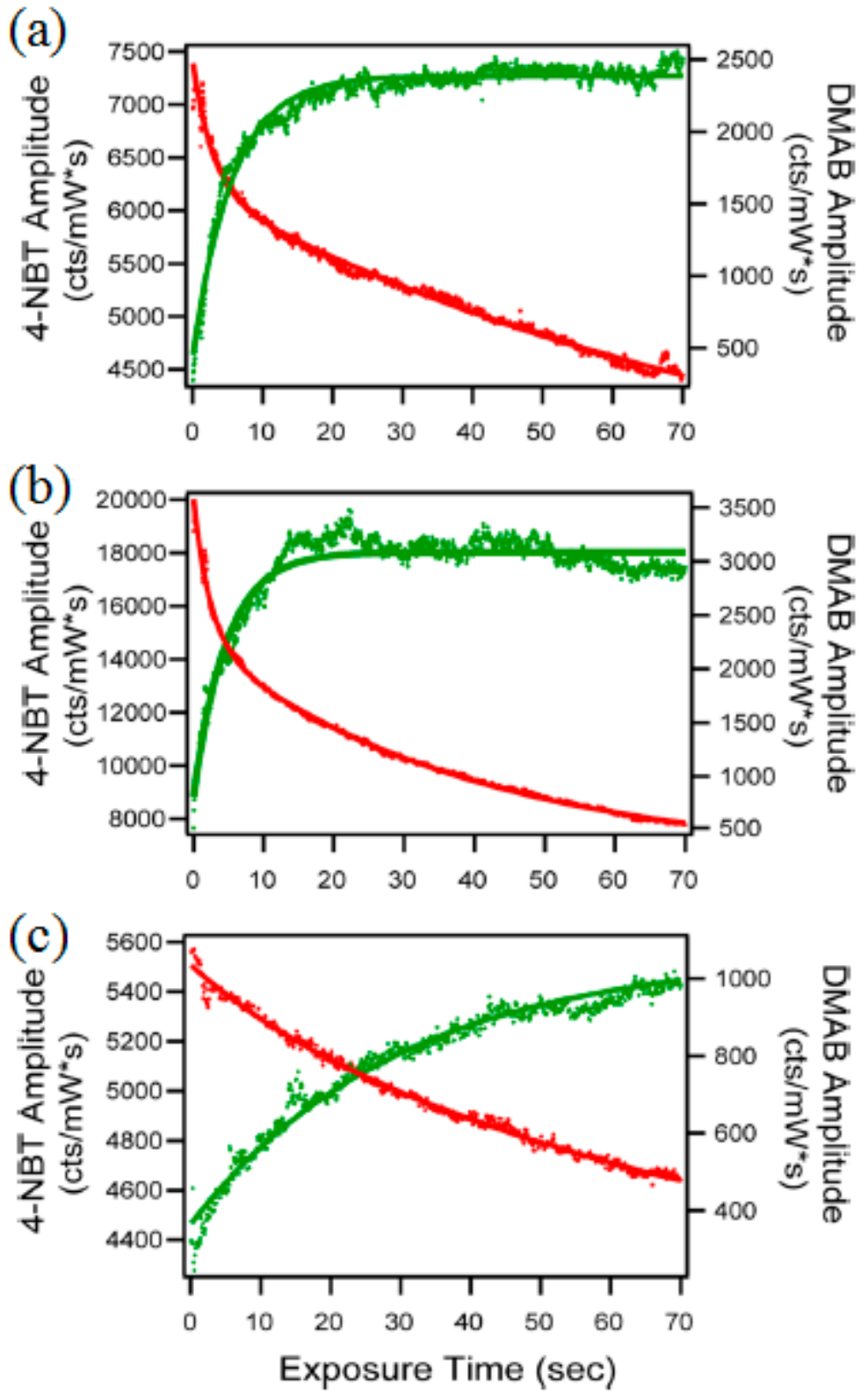

Figure 10. Reaction kinetics of 4NBT to DMAB plasmon-induced photoreactions. (a) The 4NBT reactant amplitude rapidly decreases with concurrent growth of product amplitude. At longer times, reactant peak experiences additional decay, while product amplitude remains constant; (b) similar to (a), but with a slight decrease in product amplitude at longer times; (c) in a weakly enhancing environment, reactions occur more slowly [45].

From Figure 10a,b, it can be found that 4NBT amplitude gradually decreased, and a strange phenomenon occurred after reactions proceeded for approximately $30 \mathrm{~s}$. The 4 NBT amplitude quickly decreased, but the DMAB amplitude was substantially unchanged. As demonstrated in Figure 10b, the authors detected minor decrease in the signal of DMAB amplitude, indicating a similar degradation-reaction process. However, it can be seen in Figure 10c that 4NBT signal amplitude did not significantly decrease, and exhibited a lower mean field enhancement. In this region, the rate of 4 NBT reduction was very slow and consistent with DMAB product-formation kinetics.

Figure 11a displays the relationship between the photoreaction rate constant and the field enhancement. This was achieved by measuring product increase and reactant reduction. In general, the rate constant for reactant loss was generally higher compared to the rate constant of product 
increase, although the two constants were independent of the SERS EF. Thus, the rate-limiting stage of the photoconversion of the 4 NBT molecule to DMAB reduction was independent of plasmon-field enhancement. In addition, the hydration layer was the root cause of the difference in photoreaction rate constants of the reactants and product. Studies showed that, in order for the reaction to better proceed, the nitro 4NBT group should be reduced, and protonation is needed to produce reaction intermediates [50-54]. In addition, the protons that came from the hydration layer on the Au surface were needed to limit the photoreaction rate [35-39].

Figure $11 \mathrm{~b}$ displays the relationship between the rate constant of 4 NBT degradation and photoreactions and field enhancement. Similarly, there was no significant relationship between field enhancement and rate constant for the scope of observed SERS EFs. Studies showed that, for other detection areas, the photoreaction rate constant was significantly higher than the degradation rate constant. This indicated that the reaction process was generally much quicker than degradation, which resulted in loss of light due to prolonged light exposure.

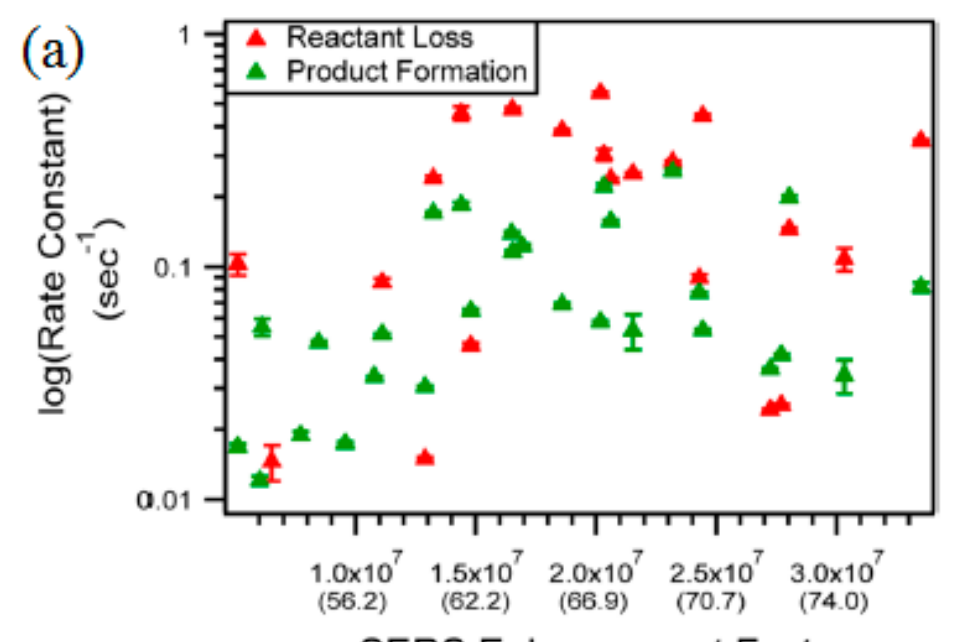

SERS Enhancement Factor

(Electric Field Enhancement)

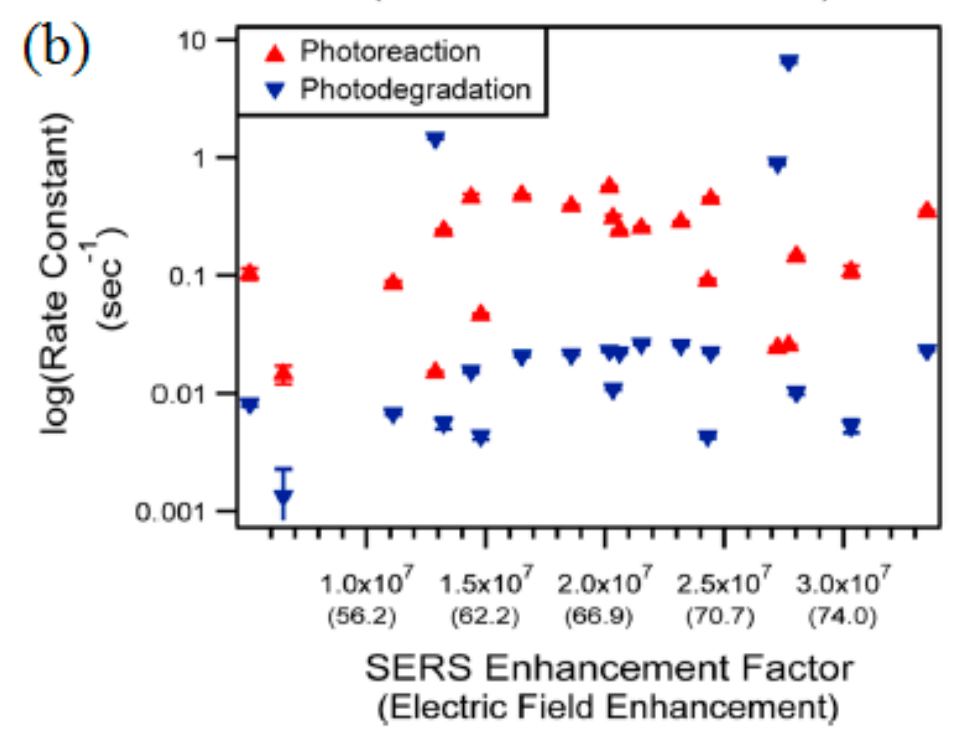

Figure 11. Rate constants for plasmon-induced processes. (a) Comparison of photoreaction rate constants with the loss of the $4 \mathrm{NBT}$ reactant (red), and formation of the DMAB product (green); (b) comparison of the photoreaction rate for 4NBT (red) and the photodegradation rate of 4NBT (blue). All observed ensemble-averaged rates are independent of field enhancement for the range of probed EFs [45]. 


\section{Conclusions}

In this review, we described plasmon catalyzed applications, such as plasmon-driven dissociations of hydrogen, nitrogen, water, and carbon dioxide. Photoreaction and degradation processes dominated under different environmental conditions. Therefore, in order to improve the rate of plasmon-driven processes for different chemical reactions, we should carefully consider a variety of photoinduced correlation rates.

In this work, we briefly introduced two ways to synthesize DMAB, and studied the photosynthetic reduction reaction and degradation process of $4 \mathrm{NBT}$ to $\mathrm{DMAB}$, as well as the competitive relationship between reaction and degradation pathways. Note that the rate constant during competition is important because the degradation effect is usually more pronounced in a high field-enhancement region. The photosynthetic reaction was faster than the degradation process. However, in all regions, reactants were continuously reduced due to the progress of the degradation reaction, so a method of optimizing the process is to cause the photosynthetic reaction to occur before the degradation reaction, which effectively avoids the above problems.

In the future, plasmon-exciton interaction can promote efficiency and probability for plasmon-driven chemical reactions. Detailed information can be obtained from References $[8,14,18,19,53-55]$.

Author Contributions: Resources, J.W.; data curation, Z.G. and J.J.; writing_original draft preparation, Z.G. and J.J.; writing-review and editing, Z.G. and J.W.; supervision, J.W.; project administration, J.W.; funding acquisition, J.W.

Funding: This work was supported by the National Nature Science Foundation of China (Grant No. 91436102, 11374353), the Fundamental Research Funds for the Central Universities, and the Talent Scientific Research Fund of LSHU (No. 6008).

Conflicts of Interest: The authors declare no conflicts of interest.

\section{References}

1. Sun, M.; Zhang, Z.; Wang, P.; Li, Q.; Ma, F.; Xu, H. Remotely excited Raman optical activity using chiral plasmon propagation in Ag nanowires. Light Sci. Appl. 2013, 2, e112. [CrossRef]

2. Quan, J.; Cao, E.; Mu, X.; Sun, M. Surface catalytic reaction driven by plasmonic waveguide. Appl. Mater. Today 2018, 11, 50-56. [CrossRef]

3. Fang, Y.; Zhang, Z.; Sun, M. High vacuum tip-enhanced Raman spectroscope based on a scanning tunneling microscope. Rev. Sci. Instrum. 2016, 87, 033104. [CrossRef] [PubMed]

4. Wang, J.; Qiao, W.; Mu, X. Au Tip-Enhanced Raman Spectroscopy for Catalysis. Appl. Sci. 2018, 8, 2026. [CrossRef]

5. Lin, W.; Ren, X.; Cui, L.; Zong, H.; Sun, M. Electro-optical tuning of plasmon-driven double reduction interface catalysis. Appl. Mater. Today 2018, 11, 189-192. [CrossRef]

6. Lin, W.; Xu, X.; Quan, J.; Sun, M. Propagating surface plasmon polaritons for remote excitation surface-enhanced Raman scattering spectroscopy. Appl. Spectrosc. Rev. 2018, 53, 771-782. [CrossRef]

7. Cao, E.; Lin, W.; Sun, M.; Liang, W.; Song, Y. Exciton-plasmon coupling interactions: From principle to applications. Nanophotonics 2018, 7, 145-167. [CrossRef]

8. Liu, W.; Lin, W.; Zhao, H.; Wang, P.; Sun, M. The nature of plasmon-exciton codriven surface catalytic reaction. J. Raman Spectrosc. 2017, 49, 383-387. [CrossRef]

9. Zhang, Z.; Sheng, S.; Wang, R.; Sun, M. Tip-Enhanced Raman Spectroscopy. Anal. Chem. 2016, 88, 9328-9346. [CrossRef]

10. Wang, X.; Cao, E.; Zong, H.; Sun, M. Plasmonic electrons enhanced resonance Raman scattering (EERRS) and electrons enhanced fluorescence (EEF) spectra. Appl. Mater. Today 2018, 13, 298-302. [CrossRef]

11. Sun, M.T.; Xu, H.X. A novel application of plasmonics: Plasmon-driven surface-catalyzed reactions. Small 2012, 8, 2777-2786. [CrossRef] [PubMed]

12. Wang, J.; Mu, X.; Wang, X.; Wang, N.; Ma, F.; Liang, W.; Sun, M. The thermal and thermoelectric properties of in-plane C-BN hybrid structures and graphene/h-BN van der Waals heterostructures. Mater. Today Phys. 2018, 5, 29-57. [CrossRef] 
13. Li, R.; Zhang, Y.; Xu, X.; Zhou, Y.; Chen, M.; Sun, M. Optical characterizations of two-dimensional materials using nonlinear optical microscopies of CARS, TPEF, and SHG. Nanophotonics 2018, 7, 873-881. [CrossRef]

14. Lin, W.; Cao, Y.; Wang, P.; Sun, M. Unified treatment for plasmon-exciton co-driven reduction and oxidation reactions. Langmuir 2017, 33, 12102-12107. [CrossRef] [PubMed]

15. Ding, Q.; Li, R.; Chen, M.; Sun, M. Ag nanoparticles- $\mathrm{TiO}_{2}$ film hybrid for plasmon-exciton co-driven surface catalytic reactions. Appl. Mater. Today 2017, 9, 251-258. [CrossRef]

16. Fang, Y.; Li, Y.; Xu, H.; Sun, M. Ascertaining p,p-dimercaptoazobenzene produced from p-aminothiophenol by selective catalytic coupling reaction on silver nanoparticles. Langmuir 2010, 26, 7737-7746. [CrossRef] [PubMed]

17. Li, P.; Ma, B.; Yang, L.; Liu, J. Hybrid single nanoreactor for in situ SERS monitoring of plasmon-driven and small Au nanoparticles catalyzed reactions. Chem. Commun. 2015, 51, 11394-11397. [CrossRef]

18. Cao, E.; Guo, X.; Zhang, L.; Shi, Y.; Lin, W.; Liu, X.; Fang, Y.; Zhou, L.; Sun, Y.; Song, Y.; et al. Electroopical synergy on plasmon-exciton-codriven surface reduction reactions. Adv. Mater. Interfaces 2017, 4, 1700869. [CrossRef]

19. Lin, W.; Cao, E.; Zhang, L.; Xu, X.; Song, Y.; Liang, W.; Sun, M. Electrically enhanced hot hole driven oxidation catalysis at the interface of a plasmon-exciton hybrid. Nanoscale 2018, 10, 5482-5488. [CrossRef]

20. Sun, M.; Zhang, Z.; Zheng, H.; Xu, H. In-situ plasmon-driven chemical reactions revealed by high vacuum tip-enhanced Raman spectroscopy. Sci. Rep. 2013, 2, 647. [CrossRef]

21. Choi, H.K.; Shon, H.K.; Yu, H.; Lee, T.G.; Kim, Z.H. b2 Peaks in SERS Spectra of 4-Aminobenzenethiol: A Photochemical artifact or a real chemical enhancement? J. Phys. Chem. Lett. 2013, 4, 1079-1086. [CrossRef] [PubMed]

22. Sun, M.; Fang, Y.; Zhang, Z.; Xu, H. Activated vibrational modes and Fermi resonance in tip-enhanced Raman spectroscopy. Phys. Rev. E 2013, 87, 020401. [CrossRef] [PubMed]

23. Van Schrojenstein Lantman, E.M.; Deckert-Gaudig, T.; Mank, A.J.; Deckert, V.; Weckhuysen, B.M. Catalytic processes monitored at the nanoscale with tip-enhanced Raman spectroscopy. Nat. Nanotechnol. 2012, 7, 583-586. [CrossRef] [PubMed]

24. Xie, W.; Walkenfort, B.; Schiucker, S. Label-free SERS monitoring of chemical reactions catalyzed by small gold nanoparticles using 3D plasmonic superstructures. J. Am. Chem. Soc. 2013, 135, 1657-1660. [CrossRef] [PubMed]

25. Kim, K.; Choi, J.Y.; Shin, K.S. Photoreduction of 4-nitrobenzenethiol on Au by hot electrons plasmonically generated from Ag nanoparticles: Gap-mode surface-enhanced Raman scattering observation. J. Phys. Chem. C 2015, 119, 5187-5194. [CrossRef]

26. Lee, S.J.; Kim, K. Surface-induced photoreaction of 4-nitrobenzenethiol on silver: Influence of SERS-active sites. Chem. Phys. Lett. 2003, 378, 122-127. [CrossRef]

27. Shin, K.S.; Lee, H.S.; Joo, S.W.; Kim, K. Surface-induced photoreduction of 4-nitrobenzenethiol on Cu revealed by surface enhanced Raman scattering spectroscopy. J. Phys. Chem. C 2007, 111, 15223-15227. [CrossRef]

28. Mia, X.; Wang, Y.; Li, R.; Sun, M.; Zhang, Z.; Zheng, H. Multiple surface plasmon resonances enhanced nonlinear optical microscopy. Nanophotonics 2019, 8. [CrossRef]

29. Dong, B.; Fang, Y.; Chen, X.; Xu, H.; Sun, M. Substrate-, wavelength-, and time-dependent plasmon-assisted surface catalysis reactions of 4-nitrobenzenethiol dimerizing to $\mathrm{p}, \mathrm{p}^{\prime}$-dimercaptoazobenzene on $\mathrm{Au}, \mathrm{Ag}$, and Cu films. Langmuir 2011, 27, 10677-10682. [CrossRef]

30. Kim, K.; Kim, K.L.; Shin, K.S. Photoreduction of 4,4'-dimercaptoazobenzene on Ag revealed by Raman scattering spectroscopy. Langmuir 2013, 29, 183-190. [CrossRef]

31. Zhang, Z.; Xu, P.; Yang, X.; Liang, W.; Sun, M. Surface plasmon-driven photocatalysis in ambient, aqueous and high-vacuum monitored by SERS and TERS. J. Photochem. Photobiol. C Photochem. Rev. 2016, 27, 100-112. [CrossRef]

32. Zhang, Q.; Wang, H. Facet-dependent catalytic activities of Au nanoparticles enclosed by high-index facets. ACS Catal. 2014, 4, 4027-4033. [CrossRef]

33. Brongersma, M.L.; Halas, N.J.; Nordlander, P. Plasmon-induced hot carrier science and technology. Nat. Nanotechnol. 2015, 10, 25-34. [CrossRef] [PubMed]

34. Xu, X.; Shi, Y.; Liu, X.; Sun, M. Femtosecond dynamics of monolayer $\mathrm{MoS}_{2}-\mathrm{Ag}$ nanoparticles hybrid probed at $532 \mathrm{~nm}$. Chem. Phys. Lett. 2018, 692, 208-213. 
35. Hou, W.; Cronin, S.B. A review of surface plasmon resonance-enhanced photocatalysis. Adv. Funct. Mater. 2013, 23, 1612-1619. [CrossRef]

36. Lin, W.; Shi, Y.; Yang, X.; Li, J.; Cao, E.; Xu, X.; Pullerits, T.; Liang, W.; Sun, M. Physical mechanism on exciton-plasmon coupling revealed by femtosecond pump-probe transient absorption spectroscopy. Mater. Today Phys. 2017, 3, 33-40. [CrossRef]

37. Mukherjee, S.; Libisch, F.; Large, N.; Neumann, O.; Brown, L.V.; Cheng, J.; Lassiter, J.B.; Carter, E.A.; Nordlander, P.; Halas, N.J. Hot electrons do the impossible: Plasmon-induced dissociation of $\mathrm{H}_{2}$ on $\mathrm{Au}$. Nano Lett. 2013, 13, 240-247. [CrossRef] [PubMed]

38. Amenomiya, Y. Adsorption of hydrogen and $\mathrm{H}_{2}-\mathrm{D}_{2}$ exchange reaction on alumina. J. Catal. 1971, 22, $109-122$. [CrossRef]

39. Mubeen, S.; Lee, J.; Singh, N.; Kramer, S.; Stucky, G.D.; Moskovits, M. An autonomous photosynthetic device in which all charge carriers derive from surface plasmons. Nat. Nanotechnol. 2013, 8, 247-251. [CrossRef]

40. Liu, Z.; Hou, W.; Pavaskar, P.; Aykol, M.; Cronin, S.B. Plasmon resonant enhancement of photocatalytic water splitting under visible illumination. Nano Lett. 2011, 11, 111-1116. [CrossRef]

41. Hou, W.; Hung, W.H.; Pavaskar, P.; Goeppert, A.; Aykol, M.; Cronin, S.B. Photocatalytic conversion of $\mathrm{CO}_{2}$ to hydrocarbon fuels via plasmon-enhanced absorption and metallic interband transitions. ACS Catal. 2011, 1, 929-936. [CrossRef]

42. Kleinman, S.L.; Frontiera, R.R.; Henry, A.L.; Dieringer, J.A.; Van Duyne, R.P. Characterizing, and controlling chemistry with SERS hot spots. Phys. Chem. Chem. Phys. 2013, 15, 21-36. [CrossRef] [PubMed]

43. Valley, N.; Greeneltch, N.; Van Duyne, R.P.; Schatz, G.C. A look at the origin and magnitude of the chemical contribution to the enhancement mechanism of surface-enhanced Raman spectroscopy (SERS): Theory and experiment. J. Phys. Chem. Lett. 2013, 4, 2599-2604. [CrossRef]

44. Mccreery, R.L. Raman Spectroscopy for Chemical Analysis; Wiley-Interscience: New York, NY, USA, 2000.

45. Brooks, J.L.; Frontiera, R.R. Competition between reactions and degradation pathways in plasmon-driven photochemistry. J. Phys. Chem. C 2016, 120, 20869-20876. [CrossRef]

46. Skadtchenko, B.O.; Aroca, R. Surface-enhanced Raman scattering of p-nitrothiophenol. Spectrochim. Acta Part A 2001, 57, 1009-1016. [CrossRef]

47. Kim, K.; Shin, D.; Kim, K.L.; Shin, K.S. Surface-enhanced Raman scattering of 4,4'-dimercaptoazobenzene trapped in Au nanogaps. Phys. Chem. Chem. Phys. 2012, 14, 4095-4100. [CrossRef]

48. Hao, E.; Schatz, G.C. Electromagnetic fields around silver nanoparticles and dimers. J. Chem. Phys. 2004, 120, 357-366. [CrossRef]

49. Stranahan, S.M.; Willets, K.A. Super-resolution optical imaging of single-molecule SERS hot spots. Nano Lett. 2010, 10, 3777-3784. [CrossRef]

50. Xu, P.; Kang, L.; Mack, N.H.; Schanze, K.S.; Han, X.; Wang, H.L. Mechanistic understanding of surface plasmon assisted catalysis on a single particle: Cyclic redox of 4-aminothiophenol. Sci. Rep. 2013, 3, 2997. [CrossRef]

51. Dong, B.; Fang, Y.R.; Xia, L.; Xu, H.X.; Sun, M.T. Is 4-nitrobenzenethiol converted to p, $\mathrm{p}^{\prime}$-dimercaptoazobenzene or 4-aminothiophenol by surface photochemistry reaction? J. Raman Spectrosc. 2011, 42, 1205-1206. [CrossRef]

52. Wang, J.; Wang, X.; Mu, X. Plasmonic Photocatalysts Monitored by Tip-Enhanced Raman Spectroscopy. Catalysts 2019, 9, 109. [CrossRef]

53. Wang, J.; Lin, W.; Xu, X.; Ma, F.; Sun, M. Plasmon-Exciton Coupling Interaction for Surface Catalytic Reactions. Chem. Rec. 2018, 18, 481-490. [CrossRef] [PubMed]

54. Wang, J.; Feng, N.; Sun, Y.; Mu, X. Nanoplasmon-Semiconductor Hybrid for Interface Catalysis. Catalysts 2018, 8, 429. [CrossRef]

55. Cao, E.; Sun, M.; Song, Y.; Liang, W. Exciton-plasmon hybrids for surface catalysis detected by SERS. Nanotechnology 2018, 29, 372001. [CrossRef] [PubMed]

(C) 2019 by the authors. Licensee MDPI, Basel, Switzerland. This article is an open access article distributed under the terms and conditions of the Creative Commons Attribution (CC BY) license (http://creativecommons.org/licenses/by/4.0/). 